\title{
Location, Number and Morphology of Parathyroid Glands: An Anatomical Study in Surgical Series
}

\author{
Bode Rovena $^{1 *}$, Dracini Xheladin¹, Celiku Etmond ${ }^{1}$, Nikollaq Leka ${ }^{2}$ and Arben Mitrushi \\ ${ }^{1}$ Department of General Surgery, “Mother Teresa” University Hospital Center, Tirana, Albania
}

${ }^{2}$ Department of Normal Anatomy, Medicine University of Tirana, Albania

*Corresponding author: Rovena Bode, Surgery Department of General Surgery, "Mother Teresa” University Hospital Center, Rruga e Dibres, 1025 Tirana, Albania

Submission: 傮 January 09, 2018; Published: 眥 February 21, 2018

\begin{abstract}
Aim of study: The aim of the study is to investigate the frequency of parathyroid gland variations, especially location, shape and number variation during thyroidectomy.

Materials and methods: The study involved a number of 137 patients, who underwent thyroidectomy between January 2010 -January 2013 Parathyroid glands are studied for determining anatomical variations, especially location variations, shape and number.

Results: A number of 452 parathyroid glands were identified. The anatomical norm of number was $4 \mathrm{gl} / \mathrm{ps}$ found in $62 \%$ of patients. Number variations resulted from 2, 3 and $5 \mathrm{gl} / \mathrm{ps}$. Most parathyroid glands were found in oval/beanlike shape in $54 \%$ of cases. Other shape variations were found in $46 \%$. Ectopy was found in $8.2 \%$ of glands, of them superior parathyroids were ectopic in $6 \%$ of cases, inferior parathyroids in $9.6 \%$ of them. Variation in location was found approximately in $13.7 \%$ for superior parathyroids and $41.7 \%$ in inferior parathyroids.
\end{abstract}

Discussion: Anatomical knowledge, identification and preservation of glands are necessary for a secure and successful thyroid and parathyroid gland surgery. This study shows that despite the wide distribution, the normal parathyroid glands falls into a definite pattern, and can be uncovered in these locations in the majority of cases.

Conclusions: Anatomical knowledge of parathyroid anatomy and its variations is essential in thyroid and parathyroid surgery in order to minimize the rate of thyroid surgery morbidity, especially lesions of parathyroid glands, their iatrogenic excision and laryngeal nerves damage.

Keywords: Parathyroids; Orthotopy; Ectopy; Variations

Abbreviations: ITA: Inferior Thyroid Artery; Gls: Glands; HPT1: Primary Hyperparathyroidism; HPT2: Secondary Hyperparathyroidism; LL: Left Lobectomy; MNG: Multinodular Goiter; M Basedov: Morbus Bazedov; PGs: Parathyroid Glands; PIII: Inferior Parathyroid Glands; PIV: Superior Parathyroid Glands; Pts: Parathyroids; PHPT: Primary Hyperparathyroidism; RLN: Recurrent Laryngeal Nerve; RL: Right Lobectomy; ST: Subtotal Thyroidectomy; TT: Total Thyroidectomy; TG: Thyroid Gland; TZ: Tuberculum of Zuckerkandle; UPG: Undescended Parathyroid Glands

\section{Introduction}

Parathyroid glands are endocrine organs, organized in two pairs, localized in the cervical region, on both sides of visceral axis of the neck, along the posterior surface of the lateral lobes of the thyroid gland. They are situated in the fibrous tissue close to the junction of RLN and ITA, PIII found ventraly to the NLR, while PIV dorsaly to NLR [1,2]. Typically there are four parathyroid glands: two superior and two inferior. Gilmour \& Martin [3] in an autopsy study of 527 cadaveric bodies, noted that the normal number of four parathyroid glands was found in $80 \%$ of cases $[2,3]$. Parathyroid glands are characterized of a soft, pliable consistency and inelasticity, which accounts for its variety of shape. They may be oval, spherical, bean like, teardrop like, reniform, pancake, leaf, oblongated, belobated [1,2,4-6].
In fact topography (localization and reports) of parathyroid glands varies widely as a result of the degree of migration during embryonic development. The fourth brankial pouch, will contribute in the origin of the superior parathyroid glands (PIV). They will migrate to the lateral thyroid to the point of penetration of ITA having a limited distribution area, with a much shorter embryologic descent, but possible ectopies [1,3,6-8]. While the inferior parathyroid glands will arise from the dorsal part of the third pharyngeal pouch endoderm (PIII) [5]. Starting at the region of the pharyngeal wall, they migrate inferior and medially in the neck, separating from thymus tissue before it enters the anterior mediastinum, at the lower pole of thyroid gland. This long course of descent can lead to a large area of possible ectopic positions of inferior parathyroid glands from the level of mandibular angle to the pericardium $[1,3-5,8,9]$. 


\section{Material and Methods}

It is a unicentric, prospective, descriptive study, with analytic components, carried on the University Hospital Center "Mother Teresa" of Tirana, in the service of General Surgery in collaboration with the Department of Morphology. It is focused on 137 patients, submitted for thyroid surgery, during the period January 2010-January 2013. A prospective database was maintained into which anatomical, patient demographic and other clinicpathological details were entered after surgery.

A. The inclusion criteria were: benign multinodular goiter toxic multinodular goiter, Basedov disease, toxic adenoma, cold nodules, thyroid carcinoma (T1/T2, N0, M0).

B. The exclusion criteria were: previous thyroid surgery, advanced thyroid carcinoma, neck reoperations.

C. Surgical procedures conducted were: total thyroidectomy (TT) \pm lymphatic dissection (LD), subtotal thyroidectomy (ST), Right Lobectomy (RL)+ istmectomy, and left lobectomy (LL)+ istmectomy.

The surgical technique, employed in most cases in the present series was a capsular dissection technique, according to Delbridge [10], paying attention to the parathyroid blood supply.

The parathyroid glands were "watched out for", their characteristics, evaluated especially the relations to RLN and ITA. Criteria used to positively identify parathyroid glands were dimensions on the average $5 \times 3 \times 1 \mathrm{~mm}$ (despite numerous variations), the characteristic colour (caramel, yellow-brown) dependent on the amount of fatty tissue and degree of blood supply, and consistency (firm, non friable) [2,3]. In fact dimensions, colour and consisteny cannot be used as the sole determinants of identification and normalcy of the gland [2,3]. Positive identification of parathyroid was made only when the senior author was confident that parathyroid was unequivocally identified. Superior parathyroid glands are found dorsally to the RLN, and the inferior parathyroid glands are found ventrally to the nerve. If it cannot be found in ortotopic location should be searched in ectopic positions [11].

If parathyroid gland is not easily recognized, a careful intraoperatively examination of the surgical specimen (thyroid gland) should be performed, for the possibility of immediate autotransplantation into a pocket fashioned in the ipsilateral sternocleidomastoid muscle [12-15]. Study is based on the evaluation of parathyroid glands location, comparing glands relation to similar anatomical landmark as cricothyroid junction, inferior pole of thyroid, superior pole of thyroid, thymic tongue and the mediastinal thymus. "Anatomical norm" of location was defined as the presence of demanded PG within a circumscribed area of $2 \mathrm{~cm}$ diameter, $1 \mathrm{~cm}$ cranially to intersection of ITA and RLN, according to Bonjer \& Bruining [16].

Anatomical variations defined as individual difference of normal anatomy or baseline pattern, simply by spatial placement, result clinically asymptomatic, fully healthy individuals. While anatomical abnormalities are errors of embryonic development related to failure of migration or a prolonged migration of PGs, and clinically do not have concerns. They make significance when PGs are pathological (adenoma, carcinoma, PGs hyperplasia) and located in ectopic position or when are supernumerary.

\section{Results}

A total of 137 patients were subjected to thyroidectomy, of whom 24 males and 113 females, operated in the 1st Service of General Surgery during January 2010- January 2013. This included 53 total thyroidectomies (TT) and 57 subtotal thyroidectomies (ST). Of the remaining cases there were 10 right lobectomies (RL) and 17 left lobectomies (LL) associated with istmectomy. Patient's age ranges from 13 to 80 years old. The mean age was 44.56 years old (yrs). Male: female ratio was 1:4.7. The mean age of males was 44.6 $+/-15 y$ yrs. The mean age of females was $42.4+/-13 y r s$. There were identified a total of 112 right superior PGs, 121 left superior PGs, 107 right inferior PGs, 111 left inferior PGs and one supernumerary gland. There were 233 superior PGs and 219 inferior PGs, for a total of 452 identified PGs (91.3\%) of 495 glands.

Table 1: Number of identified/non identified PGs.

\begin{tabular}{|c|c|c|c|}
\hline Location & Identified (\%) & Non-identified (\%) & Total (\%) \\
\hline Right sup PG* & $112(93.3)$ & $8(6.7)$ & $120(100.0)$ \\
\hline Right inf PG* & $107(89.0)$ & $13(11.0)$ & $120(100.0)$ \\
\hline Left sup PG* & $121(96.0)$ & $6(4.0)$ & $126(100.0)$ \\
\hline Left inf PG* & $112(88.8)$ & $16(11.2)$ & $126(100.0)$ \\
\hline Total & $452(100.0)$ & $43(100.0)$ & $495(100.0)$ \\
\hline
\end{tabular}

Superior PGs are identified in 94\% of them, in 6\% wasn't possible to visualize them. Inferior PGs were identified in $88.3 \%$ of them. In $11.7 \%$ of them it wasn't possible to identify (Table 1). Among the visualized glands, superior parathyroids were found in ortothopic positions in $94 \%$ of them and in ectopic positions in $6 \%$ of them. Among the inferior glands ortothopy is found in $90.4 \%$ of cases and ectopy in $9.6 \%$.

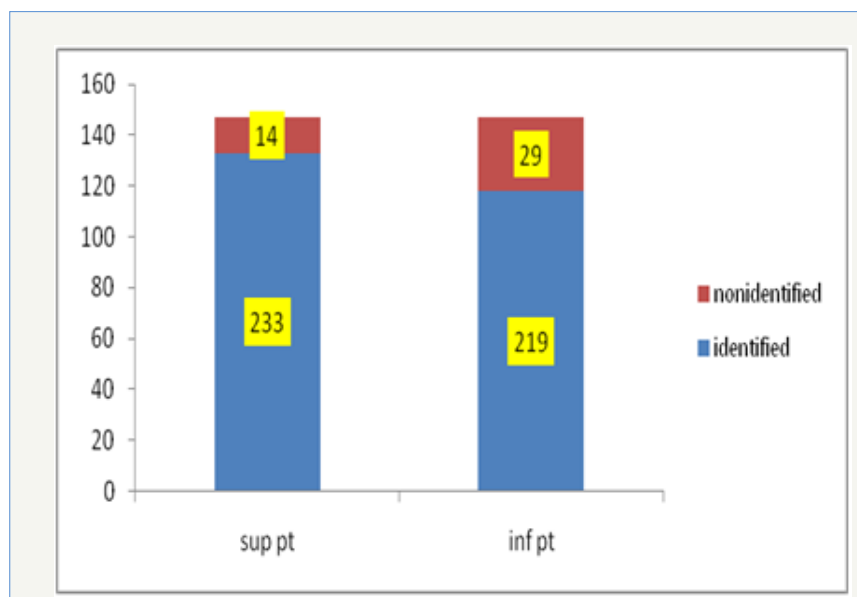

Figure 1: Graphical representation of identified against unidentified glands.

Figure 1 indicates, that inferior PGs have a higher nonidentifiable proportion than superior PGs. This we believe, as a conseguence of the marked location variability of these glands, the tendency to extend towards the mediastinum as a part of cervico- 
mediastinal thymus, or retropharyngeal/oesophageal locations, which through a cervicotomy approach for thyroidectomy are difficult to be identified more than are number variations. This we believe it is related to the impossibility for extended surgical dissections or wide anatomical explorations, which itself puts at risk PGs and RLN [1-11].

In the present study the highest number of PGs identified was 5 , and it belongs to a patient with PHP. The smallest number was 1gland, identified in 4 patients, where it was done right/left lobectomy. Limitation of surgical procedure has conditioned the limited exploration and restrictions in glands identifications. Two glands are identified in 23 patients, three (3) glands are identified on 39 subjects and four (4) glands were identified on 71subjects.

\section{Study of the number of parathyroid glands}

Regarding number variations of PGs, we studed this variable in patients were the performed procedure was total/subtotal thyroidectomy, in 110 subjects were had the opportunity to visualize them. We excluded patients who have undergone right/left lobectomy. According to these results, the most frequent number (Norm) of parathyroid glands/person is four (4), encountered in $62 \%$ of cases

Table 2: Number variations of PGs.

\begin{tabular}{|c|c|c|c|}
\hline Glands number & Males (\%) & Female (\%) & Total (\%) \\
\hline 2 glands & $1(0.0)$ & $2(0.0)$ & $3(3.3)$ \\
\hline $3 \ldots \ldots \ldots$ & $6(35.2)$ & $32(34.4)$ & $38(34.5)$ \\
\hline $4 \ldots \ldots .$. & $9(52.9)$ & $59(63.4)$ & $68(62.1)$ \\
\hline $5 \ldots \ldots \ldots$. & $1(5.9)$ & $0(0.0)$ & $1(1.1)$ \\
\hline Total & $17(100.0)$ & $93(100.0)$ & $110(100.0)$ \\
\hline
\end{tabular}

While variations in the number present as: (3) three glands in $34.5 \%$ of cases, without gender differences. In only $3(3.3 \%)$ subjects 2 glands/person were identified. And this we believe, as a result of abnormal position (ectopies) rather than of number variations. In one case a subject with $5 \mathrm{gls}$, a supernumerary PGs is found with an average of $3.65 \mathrm{gls} /$ person (Table 2).

\section{Anatomic study of shape}

Table 3: Variations in shape of normal parathyroid glands.

\begin{tabular}{|c|c|c|c|c|}
\hline \multirow{2}{*}{ Shape } & \multicolumn{2}{|c|}{ Gender(\%) } & \multirow{2}{*}{ Total(\%) } & \multirow{2}{*}{ P value* } \\
\cline { 2 - 3 } & Male & Female & & \\
\hline Ovale & $31(24.6)$ & $106(32.5)$ & $137(28.0)$ & 0.09 \\
\hline Spherical & $27(21.4)$ & $56(17.2)$ & $83(18.0)$ & 0.3 \\
\hline Reniform & $26(20.6)$ & $87(26.7)$ & $113(26.0)$ & 0.09 \\
\hline Plane & $10(7.9)$ & $23(7.0)$ & $33(9.0)$ & 0.344 \\
\hline Oblongata & $24(19.0)$ & $48(14.7)$ & $72(20.0)$ & 0.16 \\
\hline Bi/multilobate & $8(6.3)$ & $6(1.8)$ & $14(5.0)$ & 0.061 \\
\hline Total & $126(100.0)$ & $326(100.0)$ & $452(100.0)$ & \\
\hline
\end{tabular}

*significance level $\mathrm{P} \leq 0.05$.

The most common forms we found were oval shape in $28 \%$ of specimen. Meanwhile, reniform-bean like shape glands are just as common with $26 \%$ of specimen. The others are spherical and elongated shape glands (Table 3). Elongated shape glands were found in $20 \%$ of cases, followed by spherical shape glands in $18 \%$ of cases. Also bi/multilobate shape glands are present with $5 \%$ of specimen. Significant difference in gender distribution of glands were not found.

Table 4: Parathyroid glands in orthotopic/eutopic (normal) positions and ectopic (abnormal) positions.

\begin{tabular}{|c|c|c|c|}
\hline \multirow{2}{*}{ PGs position } & Orthotopic/eutopic & Ectopic & \multirow{2}{*}{ Total (\%) } \\
\cline { 2 - 3 } & $\mathbf{N r = 4 1 5 ( \% )}$ & $\mathbf{N r}=\mathbf{3 7}(\mathbf{\%})$ & \\
\hline Right superior & $104(93.7)$ & $8(6.3)$ & $112(100.0)$ \\
\hline Left superior & $114(94.4)$ & $7(5.6)$ & $121(100.0)$ \\
\hline Right inferior & $96(89.7)$ & $11(10.3)$ & $107(100.0)$ \\
\hline Left inferior & $101(91.0)$ & $11(9.0)$ & $112(100.0)$ \\
\hline Total & $415(91.8)$ & $37(8.2)$ & $452(100.0)$ \\
\hline
\end{tabular}

\section{Localisation study of normal PGs}

The study of parathyroid glands location is based on the introduction of orthotopy-ectopy definitions [12,17,18] according to which: An ectopic superior PG (P4) was defined as a gland in a location other than cricothyroidal junction, posteriorly (anatomical Norm) or within the capsule-subcapsular, on the posterior surface of the upper pole of the thyroid gland (anatomical variation) and lateropharingo-oesophageal (anatomical variation) [12-16].

An ectopic inferior PG (P3) was defined as a gland in a location other than or immediately adjacent to the anterior or poster lateral surface of the inferior pole of thyroid gland (anatomical Norm) or within the thymic tongue (anatomical variation) which represents a cervical extension of thymus and near carotid vessels(anatomical variation) [12,17-20].

About $93.7-94.4 \%$ of superior glands are found in an orthotopic location and 5.6-6.3\% are found in ectopic positions (Table 4). Inferior glands in $89.7-91 \%$ are found in eutopic positions and 9-10.3\% in ectopic locations From 218 superior PGs, 90(84.2\%) right and 96(86.5\%) left Pgs are found posterior of cricothyroid junction, which is the most common site of superior PGs. Here the gland was dorsal to the RLN, intimately related to the branches of ITA. The rest of the superior PGs lie behind the upper pole of thyroid gland, respectively $12(11.6 \%)$ in the right and $17(14.9 \%)$ in the left, lying under the pretracheal fascia, which forms the surgical capsule of the thyroid. Rare are the pharyngo oesophageal locations found in 3 cases (0.9-1.9) (Table 5).

Inferior PGs are distributed rather evenly between the lower pole of thyroid and the thymus. Off the 197 inferior gls 52(54\%) right and 54(53.4\%) left were found at the lateroposterior surface of inferior pole. Usually were placed ventrally of LRN. 79(40\%) gls are found from the thyrothymic lig toward mediastinal thymus (along thymic tongue, which is an identifiable structure from the lower pole of thyroid to mediastinal thymus). The other part lies in close raports with carotid vessels $12(6.2 \%)$. Regarding the recent study, the ectopic positions, superior parathyroid glands occupy ectopic positions like extracapsular, intrathyroidal, lateropharyngeal. Inferior ectopic parathyroid glands are found mainly in mediastinal positions (Table 6) 
Table 5: Distribution of eutopic/orthotopic positions of PGs.

\begin{tabular}{|c|c|c|}
\hline Location & Seri Nr (415) & $100(\%)$ \\
\hline \multicolumn{3}{|c|}{ Right Superior } \\
\hline Cricothyroid junction posteriorly & 90 & $(86.5)$ \\
\hline Posteriorly of superior pole & 12 & $(11.6)$ \\
\hline Pharyngeo-oesophageal junction laterally & 2 & $(1.9)$ \\
\hline \multicolumn{3}{|c|}{ Left Superior } \\
\hline Cricothyroid junction posteriorly & 96 & $(84.2)$ \\
\hline Posteriorly of superior pole & 17 & $(14.9)$ \\
\hline Pharyngeo-oesophageal junction laterally & 1 & $(0.9)$ \\
\hline \multicolumn{3}{|c|}{ Right Inferior } \\
\hline Lateroposterior surface of inferior thyroid pole. & 52 & $(54.1)$ \\
\hline Thymic tongue & 37 & $(38.5)$ \\
\hline Along carotid artery & 7 & $(7.2)$ \\
\hline \multicolumn{3}{|c|}{ Left Inferior } \\
\hline Lateroposterior surface of inferior thyroid pole. & 54 & $(53.4)$ \\
\hline Thymic tongue & 42 & $(41.6)$ \\
\hline Along carotid artery & 5 & $(4.9)$ \\
\hline Total & 415 & $(100.0)$ \\
\hline
\end{tabular}

Ectopic location distribution within the glands has been as above (Table 6). Ectopic superior parathyroid glands were found extracapsulary in $75 \%$ for right PGs and $62.5 \%$ for left PGs. Intrathyroidal location was found in $25 \%$ for sup right gls and in $37.5 \%$ for sup left gls. retropharyngeal positions were not found. For inferior parathyroid glands ectopies were totally cervicomediastinal border.

Table 6: Distribution of ectopic parathyroid glands.

\begin{tabular}{|c|cc|}
\hline Location & Nr & (\%) \\
\hline Right superior glands & 8 & 100.0 \\
\hline Superior pole extracapsular & 6 & 75.0 \\
\hline Intrathyroidale & 2 & 25.0 \\
\hline Retropharyngeale & 0 & 0.0 \\
\hline Left superior glands & 8 & 100.0 \\
\hline Superior pole extracapsular & 5 & 62.5 \\
\hline Intrathyroidale & 3 & 37.5 \\
\hline Retropharyngeale & 0 & 0.0 \\
\hline Right inferior glands & 11 & 100.0 \\
\hline Cervico-mediastinal thymus & 11 & 100.0 \\
\hline Left inferior glands & 10 & 100.0 \\
\hline Cervico- mediastinal thymus & 10 & 100.0 \\
\hline Total & 37 & 100.0 \\
\hline
\end{tabular}

\section{Evaluation of glands symmetry}

As part of the same study we evaluated the symmetry in glands localization. Symmetry study is conducted in that part of population who have undergone total/subtotal thyroidectomy, excluding patients that have undergone right/left lobectomy. There are 110 patients in whom we were able to identify all existing parathyroid tissue. Of 198 glands pairs, only 102(56\%) of them resulted symmetrically distributed. Superior parathyroid resulted symmetrical in $56.8 \%$ of them. Inferior parathyroids resulted symmetrical in only $45.7 \%$ of cases.

\section{Discussion}

The anatomical "basic model" of PGs shape, found in this study, presents the gland as an oval-shape structure in $54 \%$ of specimen. In general parathyroid glands were plain, soft and pliable in consistency. Its colour ranges from yellowish-caramel or reddishbrown, distinctive from that of a lymphnode, stromal fat and thyroid noduls. $46 \%$ of gls were presented with shape variations as: elongate forms in $20 \%$ of cases, spherical forms in $18 \%$ of cases, plane shape in $9 \%$ of gls and multilobular shape in $5 \%$ of them. Each gland had its own fibrous capsule.

Akerstörm [1] found most of them in bean- shape or reniforme in $68 \%$ of cases, and spherical shape were the least [1]. According to Gilmour \& Martin [2,3] in their different studies found 46\%- 57\% of glands in an oval/reniform form. Civalleri [4] \& Grays [5] found as a common shape, the oval or bean like, followed by the plain shape.

According to our survey results, the baseline model of PGs number or "anatomical Norm" was four (4)gls in $62 \%$ of subjects. Number variations/abnormalities were found in the remaining $38 \%$ of subjects as: three (3)gls in $34.5 \%$ of specimen and in only $3(3.3 \%)$ subjects were identified 2 (two)gls. Supernumerary PGs as a fifth PG was found in only one (1.2\%) patient, the latter in ectopicthymic location. This we believe, as a result of location anomalies, more than number abnormalities. Since the identification of glands is done during thyroidectomy procedure, in which a time limit must be taken into account, it cannot be sought and searched indefinitely, for glands abnormalities identification, especially in a 
neuroendocrine surgical field. As a consequence the proportion of supernumerary glands may be actually higher.

Akerström [1] in an autopsy study of 503 cadaveric bodies, found 4 pgs in 421 (84\%) of subjects [1]. Gilmour \& Martin [3] in their autopsy study report that the basic model of four (4) glands was found in $80 \%$ of subjects [2,3]. Civalleri [4] \& Grays [5] report numbers ranging from 72-83\%. Norris in 109 cases studied, has always found at least four PGs [6]. Alveryd in a series of 354 autopsies found in $90.6 \%$ of subjects four (4) glands [7]. Heinbach (1933) in a study of 25 cadaveric bodies found as the basic model three gls in $40 \%$ of cases, while 4 gls was found in $24 \%$ of cases [8].

In the recent study number variations of PGs were manifested as infranumerary glands: 2 gls in $3.3 \%$ of cases and 3 gls in $34.5 \%$ of subjects. Gilmour and Martin found infranumerary glands as 2 or 3 glands in $14 \%$ of cases [2,3]. Akerström [1] found only 3 gls in $18(3 \%)$ cases [1]. Alveryd in $5.1 \%$ of subjects found three gls [7]. Heinbach [8] in a study of 25 cadaveric bodies found $10(40 \%)$ subjects with 3gls, 5(20\%) subjects with 2gls [8]. Bansal [9] in his study found $26.66 \%$ of subjects with $3 \mathrm{gls}$ and $15 \%$ of subjects with 2gls [9]. According to Butterworth \& Nicholson in $7 \%$ of subjects are found $3 \mathrm{gls}[1,9]$. According to Lappas, 3 gls were present in $2 \%$ of subjects [2].

About supernumerary glands, we found one $(1.1 \%)$ patient with five PGs. Alveryd ${ }^{7}$ found in $3.5 \%$ of cases 5 glands, Wang ${ }^{12}$ in $2.5 \%$ of subjects found 5 gls, Akerstörm [1] in $13 \%$ of subjects found 5 gls, Gilmour ${ }^{2,3}$ in $6 \%$ of cases found 5 gls. Lappas [2] found supranumerary glands in $5 \%$ of cases, all these in anatomical studies. All these are "anatomical autopsy studies" which explains the significant changes in confront to our study. Meanwhile other reasons of differences are limits in surgical exploration and the possible ectopic location of glands. There are authors and studies where the frequency of supernumerary glands is up to $22-30 \%$ of specimens, this according to the kind of specimen: HPT1, HPT2, HPT3 and persistent/recurrent HPT.

Parathyroid glands have resulted in orthotopic locations in $91.8 \%$ of them and in $8.2 \%$ in ectopic positions. Superior glands were localized in $94 \%$ of them in orthotopic positions, meanwhile inferior glands in $90.4 \%$ of them were in orthotopic positions. Ectopic locations for superior PGs reach a value up to $6 \%$ while for inferior PGs $9.6 \%$ of them. Within orthotopic locations variations of positions for PIV reach up to $13.7 \%$ while for PIII reaches up to $41.7 \%$.

Lappas [21] found ectopic glands in $8.5 \%$ of the 3976 identified glands [20]. Hojaij [22] found ectopy in $42.8 \%$ of glands in a series of HPTH [21]. Wang found ectopy in $2 \%$ of glands [12]. Zerizer [23] finds the lowest valeu of ectopy in $1.4 \%$ in an imaging study of PHPT [22]. Mendoza [24] finds ectopy in 9\% of 145 cases with PHPT [23]. Al Bustami [18] found superior parathyroids in orthotopic positions in $95 \%$ of cases, while inferior parathyroids in $90.5 \%$ of them [24]. Our results are similar, without significant differences with authors like Wang [12] \& Al Bustami [24], while differences are observed with other authors like Akerstörm [1] \& Phitayakorn
R [18]. They are considerably for inferior parathyroids.

The reasons are concerning the nature of the sample where the study was done: - cadaveric dissection in a normal population, surgical dissection in normal population (without parathyroid desease, often in thyroidectomies), or surgical dissection in patients with PHPT, HPT2, persistent/recurrent HPT or imaging studies in HPT. Should be taken into consideration the fact that in autopsy studies, the possibility of cadaveric dissection is greater and dates provided are more realistic. Meanwhile studies in the surgery of HPT1/HPT2 offer higher incidences for supernumerary glands, their localization and their ectopies, which must be considered. Another reason to consider, there are no clear definitions on parathyroid ectopy.

By the study it is shown that an average of $6 \%$ of superior PGs, have ectopic positions and $9.6 \%$ of inferior PGs have ectopic locations. As seen we find values close to those of some of the authors, in particular with Al Bustami [24], Akerstörm [1] \& 0 Nanka [11] but statistically significant difference in particular for PIII positions.

\section{Conclusion}

Knowledge of the normal anatomy, its abnormalities and anatomical variations of parathyroid glands is a necessary condition for the general surgeon, in order to reduce in the minimum the level of iatrogenic injury during thyroid gland surgery. Knowledge of embryological development disorders, also takes a special importance during surgical treatment of HPT, where pathological glands can be located in ectopic positions or maybe supernumeraries, consequently causing surgery failure and persistent or recurrent HPT [25].

\section{References}

1. Akerström G, Malmaeus J, Bergstrom R (1984) Surgical anatomy of human parathyroid glands. Surgery 95(1): 14-21.

2. Gilmour J (1937) The embryology of the parathyroid glands, the thymus, and certain associated rudiments. J Pathol 45(3): 507-522.

3. Gilmour JR, Martin WJ (1987) The weight of thè parathyroid glands. J Pathol Bact 34: 431

4. Civalleri (1902) Sulle glandiole paratir dell: uomo, Policlinico.

5. Gray H (2008) Anatomy, the anatomical basis of clinical practice. (39 $9^{\text {th }}$ edn). Elsevier Churchil Livingstone, Philadelphia, USA.

6. Norris Eh. The parathyroids glands and the lateral thyroid gland in man their morphogenesis, histogenesis, topographic anatomy and prenatal grouth. Carnegie institute, Washington publications, No 479, contrib. Embryology. pp. 159-257.

7. Alveryd A (1968) Parathyroid glands in thyroid surgery I Anatomy of parathyroids glands II Postoperative hypoparathyroidism. Identification snd autotransplantation of parathyroids glands. Acta chirurgica Scandinavia 389: 1-120

8. Heinbach Jr WF (1933) A study of the number and location of the parathyroid glands in man. Anat Rec 57(3): 251-261.

9. Bansal S, Sudha Chhabra , I. Kayalvizhi , Jyoti Rohilla , Sunaina Grover et al. (2015) Variations in number and location of human parathyroid gland-a postmortem study. IJAR 3(7): 861-866. 
10. Delbridge L, Reeve TS, Khadra M, Poole AG (1992) Total thyroidectomythe technique of capsular dissection. Aust NZ J Surg 62(2): 96-99.

11. Alkerstrom G, Malmaeus J, Bergstrom R (1984) Surgical anatomy of human parathyroid glands. Surgery 95(1): 14-21.

12. Nanka O, Sedy J, Vitkova I, Libansky P, Adamek S (2006) Surgical anatomy of parathyroid glands with emphasis on parathyroidectomy. Prague Med Rep 107(2): 261-272.

13. Pyrtek LJ, Painter RL (1964) An anatomic study of the relationship of the parathyroid glands to the recurrent laryngeal nerve. Surg Gyn Obst 119: 509-512.

14. Bergamaschi R, Becouarn G, Ronceray J, Arnaud JP (1998) Morbidity of thyroid surgery. Am J Surg 176(1): 71-75.

15. Szubin L, Kacker A, Kakani R, Komisar A ,Blaugrund S (1996) The management of postthyroidectomy hypocalcemia. Ear Nose Throat J 75(9): 612-614.

16. Bode Rovena, Celiku Etmond (2016) Postoperative complications of thyroidectomy. IJSR 5(1): 2319-7064.

17. Bonjer H J, Bruining HA (1997) Technique of parathyroidectomy. In: Textbook of endocrine surgery. In: Clark O Duh HQ (Eds.), WB Saunders Company, Philadelphia, pp. 347-356.

18. Al Bustami F, Khraisha S (2009) Variations in the Anatomical Position

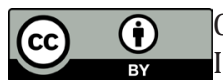

Creative Commons Attribution 4.0

nternational License

For possible submissions Click Here of the Normal and Diseased Parathyroid Glands. J Med J 43(3): 180-188.

19. Phitayakorn R, Mc Henry Cr (2006) Incidence and location of ectopic parathyroid glands. Am J Surgery 191(3): 418-423.

20. Butterworth PC, Nicholson ML (1998) Surgical anatomy of the parathyroid glands in secondary hyperparathyrpidism. J R Coll Surg Edinb 43(4): 271-273.

21. Lappas D, Noussios G, Anagnostis P, Adamidou F, Chatzigeorgiou A, et al. (2012) Location, number and morphology of parathyroid glands: results from a large anatomical series. Anat Sci Int 87(3): 160-164.

22. Hojaij F, Vanderlei F, Plopper C, Rodrigues CJ, Jacomo A, et al. (2011) Parathyroid Gland anotomical distribution and relation to anthropometric and demographic parameters: a cadaveric study. Anat Sci Int 86(4): 204-212.

23. Zerizer I, Parsaï A, Win Z, Al Nahhas A (2011) Anatomical and functional localization of ectopic parathyroid adenomas: 6-year institutional experience. Nucl Med Commun 32(6): 496-502.

24. Mendoza V, Ramírez C, Espinoza AE, González GA, Peña JF, et al. (2010) Characteristics of ectopic parathyroid glands in 145 cases of primary hyperparathyroidism. Endocr Pract 16(6): 977-981.

25. Al Bustami F, Khraisha S (2009) Variations in the Anatomical Position of the Normal and Diseased Parathyroid Glands. J Med J 43(3): 180-188.

\section{Your subsequent submission with Crimson Publishers will attain the below benefits}

- High-level peer review and editorial services

- Freely accessible online immediately upon publication

- Authors retain the copyright to their work

- Licensing it under a Creative Commons license

- Visibility through different online platforms

- Global attainment for your research

- Article availability in different formats (Pdf, E-pub, Full Text)

- Endless customer service

- Reasonable Membership services

- Reprints availability upon request

- One step article tracking system 